\title{
Cellular analysis of bronchoalveolar lavage fluid in various lung lesions
}

\author{
Punyashetty KB. ${ }^{1}$, Solanki PS. ${ }^{2 *}$, Anand SA. ${ }^{3}$ \\ DOI: https://doi.org/10.17511/jopm.2020.i02.09
}

\footnotetext{
${ }^{1}$ Kajal B. Punyashetty, Professor, Department of Pathology, Navodaya Medical College, Raichur, Karnataka, India.

2* Padma Shree Solanki, Third-year Postgraduate student, Department of Pathology, Navodaya Medical College, Raichur, Karnataka, India.

3 Anand A. S., Professor and Head, Department of Pathology, Navodaya Medical College, Raichur, Karnataka, India.
}

Introduction: Bronchoalveolar lavage (BAL) is a standard tool in the diagnosis of lung diseases. Cellular analysis of BAL fluid when deviates from normal are indicative of an inflammatory/infiltrative process. This study involves an analysis of BAL fluid performed manually and also using an automated analyzer which offers a rapid and reliable method for analysis of unprocessed BAL fluid. Aims and Objectives: To utilize the cellular analysis of bronchoalveolar lavage (BAL) fluid in the diagnosis of various lung diseases. Materials and Methods: 37 patients with pulmonary diseases of varying etiologies were included in this study. Fiberoptic bronchoscopy with BAL was performed. BAL fluid was run in SYSMEX XNL/350 six-part analyzer which gave total and differential cell count (mononuclear and polymorphonuclear cells). Results: Total WBC count ranged from 31 cells/ $\mu$ lo 94 cells $/ \mu \mathrm{l}$ with the maximum increase seen in asthma. Mononuclear cells were increased in the majority of cases, being $84 \%$ in pneumoconiosis with the predominance of macrophages. An increase in lymphocytes was seen in Non-Specific Interstitial Pneumonia (45.3\%) and Bronchiolitis Obliterans Organising Pneumonia (35.3\%), neutrophils in Usual Interstitial Pneumonia (26.2\%) and eosinophils in Chronic Eosinophilic Pneumonia (55.5\%) and asthma (8.4\%). Conclusion: BAL cell differentials when combined with additional clinical and radiographic information help secure a confident diagnosis in lung diseases and help clinicians to make therapeutic decisions.

Keywords: Automated six-part analyzer, Bronchoalveolar lavage fluid, Lung diseases

\section{Corresponding Author}

Padma Shree Solanki, Third-year Postgraduate student, Department of Pathology, Navodaya Medical College, Raichur, Karnataka, India.

Email: pssolanki12@gmail.com

\section{How to Cite this Article}

Punyashetty KB, Solanki PS, Anand AS. Cellular analysis of bronchoalveolar lavage fluid in various lung lesions. Trop J Pathol Microbiol. 2020;6(2):167173.

\section{Available From}

https://pathology.medresearch.in/index.php/jopm/ar ticle/view/437

\section{To Browse}

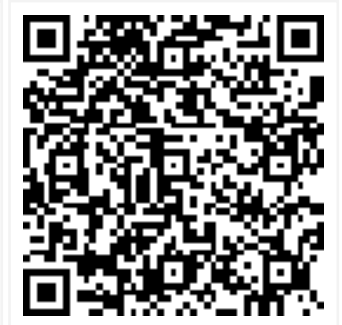

\section{Introduction}

Bronchial irrigation with saline solution was reported first by Stitt in 1927, who introduced the term "bronchial lavage" in 1932. Reynolds and Newball introduced saline lavage of a portion of the lung via the flexible bronch

$\begin{array}{cc}\begin{array}{c}\text { Manuscript Received } \\ \text { 25-01-2020 }\end{array} & \begin{array}{c}\text { Review Round } 1 \\ 06-02-2020\end{array} \\ \text { Conflict of Interest } & \text { Funding } \\ \text { No } & \text { Nil }\end{array}$
(c) 2020 by Kajal B. Punyashetty, Padma Shree Solanki, Anand AS. and Published by Siddharth Health Research and Social
Welfare Society. This is an Open Access article licensed under a Creative Commons Attribution 4.0 International License https://creativecommons.org/licenses/by/4.0/ unported [CC BY 4.0]. -oscope as a research tool in 1974 and saline lavage of a defined area of the lung became known as BAL.

BAL provides a safe and generally welltolerated means of retrieving secretions that coat the surfaces of the bronchial and alveolar epithelium [1].

\begin{tabular}{|c|c|}
\hline $\begin{array}{c}\text { Review Round } 2 \\
10-02-2020\end{array}$ & Review Round 3 \\
\hline $\begin{array}{c}\text { Ethical Approval } \\
\text { Yes }\end{array}$ & $\begin{array}{c}\text { Plagiarism X-checker } \\
14 \%\end{array}$ \\
\hline
\end{tabular}

Accepted 14-02-2020 Note 
It is a convenient procedure to apply for the diagnosis of diffuse parenchymal lung diseases [2]. It is less invasive than transbronchial and open lung biopsies and has great clinical value. Therefore, it is designated by some specialists as "liquid biopsy" [3].

The cellular analysis of BAL fluid includes total and differential cell counts and is a part of clinical routine [4]. BAL nucleated immune cell patterns that deviate from that observed in normal individuals (80-90\% alveolar macrophages, 5-15\% lymphocytes, $\leq 3 \%$ neutrophils, $\leq 1 \%$ eosinophils) are indicative of an inflammatory/ infiltrative process that has perturbed the lung airways and/or interstitium [5].

The predictive value of BAL differentials are reported to make some diagnosis more likely and exclude others [2]. Thus, BAL can provide a useful tool for the diagnosis of lung diseases when combined with aspects of clinical presentation and HRCT scanning [1].

Cell counting of BAL fluid is performed manually in routine practice. This has both methodological and inherent errors. This study utilizes an electronic automated counting device that offers a quick, precise and simple method for counting cells in unprocessed BAL fluid which is both less laborintensive and subjective than manual counting [6].

\section{Materials and Methods}

Type of study: Prospective, observational and descriptive.

Place of study: Central Research Laboratory of Navodaya medical college hospital and research center, Raichur.

Duration of study: Six months between January 2019 to June 2019.

Sample collection: The present study included a total of 37 patients with pulmonary diseases of varying etiologies. Fiberoptic bronchoscopy with BAL was performed in these patients according to a standardized protocol.

Bronchoscopic BAL fluid processing and analysis: BAL was performed by instillation of three consecutive aliquots of sterile saline solution (2030-30) $\mathrm{ml}$ into the bronchial tree at the area that was most abnormal on chest radiography. The right middle lobe or lingual segment was chosen in patients with bilateral diffuse infiltration. BAL fluid
That was first retrieved was discarded and BAL fluid that was subsequently retrieved was collected. This BAL fluid was then run in SYSMEX XNL/350 six-part analyzer which gave the total cell count and differential cell count (mononuclear and polymorphonuclear cells).

The sample was also centrifuged and sediment was smeared. The smears were prefixed with 95\% methanol and air-dried. Methanol fixed samples were stained using Papanicolaou stain. The air-dried samples were stained with Leishman stain and MGG (May-Grunwald Giemsa). Differential cell counts that included percentages of neutrophils, lymphocytes, alveolar macrophages, and eosinophils were also determined using these smeared slides.

\section{Inclusion Criteria}

- All cases included under this study were of adult age group (18 to 80 years) without any sex specifications which were referred from the Pulmonary medicine department, Navodaya medical college hospital and research center, Raichur.

- All cases which were having an indication for bronchoscopy were included.

\section{Exclusion Criteria}

- Cases with chronic obstructive lung diseases are contraindicated for bronchoscopy and thus were excluded by default in this study.

- Pediatric age group (birth to 17 years) and patients above 80 years of age were excluded in the study.

Patients who were treated with antimicrobial agents for more than 24 hours before bronchoscopic BAL.

\section{Results}

The present study involved cellular analysis of BAL fluid from 37 cases with different lung lesions. There were 8 cases of Usual Interstitial Pneumonia (UIP), 6 cases of Non-Specific Interstitial Pneumonia (NSIP), 3 cases of Bronchiolitis ObliteransOrganising Pneumonia (BOOP), 8 cases of Tuberculosis (TB), 5 cases of Pneumoconiosis, 2 cases of Chronic Eosinophilic Pneumonia (CEP), 2 cases of asthma and 3 cases of lung tumors. A male preponderance was seen with a male to female ratio being 1.3:1. The mean age of the subjects was 54years. The majority of cases belonged to the Tuberculosis (TB) and Usual Interstitial Pneumonia (UIP) group (Table 1). 
Table-1: Patient characteristics

\begin{tabular}{|l|l|l|l|l|}
\hline \multicolumn{1}{|c|}{ Disease } & $\begin{array}{r}\text { Total } \\
\text { patients }\end{array}$ & Male & Female & $\begin{array}{c}\text { Age (year) } \\
\text { (mean) }\end{array}$ \\
\hline Usual Interstitial Pneumonia (UIP) & 08 & 05 & 03 & 66 \\
\hline $\begin{array}{l}\text { Non Specific Interstitial Pneumonia } \\
\text { (NSIP) }\end{array}$ & 06 & 02 & 04 & 50 \\
\hline $\begin{array}{l}\text { Bronchiolitis Obliterans Organizing } \\
\text { Pneumonia (BOOP) }\end{array}$ & 03 & 01 & 02 & 60 \\
\hline Tuberculosis (TB) & 08 & 05 & 03 & 45 \\
\hline Pneumoconiosis & 05 & 04 & 01 & 67 \\
\hline $\begin{array}{l}\text { Chronic Eosinophilic Pneumonia } \\
\text { (CEP) }\end{array}$ & 02 & 01 & 01 & 36 \\
\hline Asthma & 02 & 01 & 01 & 38 \\
\hline Tumours & 03 & 02 & 01 & 70 \\
\hline Total & 37 & 21 & 16 & 54 \\
\hline
\end{tabular}

There was a significantly higher number of smokers (16 cases) among the male population contributing to $43.2 \%$ of the total study population. None of the female patients (16 cases) were smokers (Table 2 ).

Table-2: Smoking habit distribution of all cases

\begin{tabular}{|l|l|l|l|}
\hline \multicolumn{1}{|c|}{ Habit } & \multicolumn{1}{c|}{ Male } & \multicolumn{1}{c|}{ Female } & \multicolumn{1}{c|}{ Total } \\
\hline Smoker & $16(76.2 \%)$ & & $16(43.2 \%)$ \\
\hline Non-smoker & $05(23.8 \%)$ & $16(100 \%)$ & $21(56.8 \%)$ \\
\hline Total & $21(100 \%)$ & $16(100 \%)$ & $37(100 \%)$ \\
\hline
\end{tabular}

The total WBC count ranged from 31 cells/ $\mu$ lo 94 cells/ $\mu$ l. The maximum increase in total WBC count was seen in cases of asthma. The minimum WBC count was seen in cases of pneumoconiosis (Table 3).

Table-3: BAL cellular analysis and differential cell count on SYSMEX XNL/350 six-part analyzer

\begin{tabular}{|l|l|l|l|}
\hline Disease & $\begin{array}{c}\text { Total WBC count } \\
(\mathbf{X 1 0 3} / \mu \mathrm{LL})\end{array}$ & $\begin{array}{c}\text { Mononuclear } \\
\text { Cells }(\mathbf{X 1 0 3} / \mu \mathrm{LL})\end{array}$ & $\begin{array}{c}\text { Polymorphonuclear } \\
\text { Cells }(\mathbf{X 1 0 3} / \mu \mathrm{LL})\end{array}$ \\
\hline UIP & 0.053 & $0.024(46 \%)$ & $0.029(54 \%)$ \\
\hline NSIP & 0.087 & $0.072(83 \%)$ & $0.015(17 \%)$ \\
\hline BOOP & 0.075 & $0.066(88 \%)$ & $0.009(12 \%)$ \\
\hline TB & 0.079 & $0.046(58 \%)$ & $0.033(42 \%)$ \\
\hline $\begin{array}{l}\text { PNEUMOC } \\
\text { ONIOSIS }\end{array}$ & 0.031 & $0.026(84 \%)$ & $0.005(16 \%)$ \\
\hline CEP & 0.090 & $0.032(36 \%)$ & $0.058(64 \%)$ \\
\hline ASTHMA & 0.094 & $0.079(84 \%)$ & $0.015(16 \%)$ \\
\hline TUMOURS & 0.071 & $0.055(78 \%)$ & $0.016(22 \%)$ \\
\hline
\end{tabular}

In the majority of cases, there was an increase in mononuclear cell count with the exceptions of Usual Interstitial Pneumonia and Chronic Eosinophilic Pneumonia which showed an increase in the percentage of polymorphonuclear cells (54\% and $64 \%$ respectively) (Table 3 ). Findings on SYSMEX
XNL/350 six-part analyzer and sediment smears in various lung diseases are as follows:

01. An increase in the percentage of granulocytes (54\%) was observed in cases of UIP with a differential cell count of $44.4 \%$ macrophages, $26.2 \%$ neutrophils, $22.2 \%$ lymphocytes and 7.2\% eosinophils (Table 3 and 4).

02. The proportion of mononuclear cells inNSIP and BOOP was $83 \%$ and $88 \%$ respectively. A differential cell count of $45.3 \%$ lymphocytes, $41.6 \%$ macrophages, $7.2 \%$ neutrophils and $5.9 \%$ eosinophils in cases of NSIP and $52.7 \%$ macrophages, $\quad 35.3 \%$ lymphocytes, $8.2 \%$ neutrophils and $3.8 \%$ eosinophils in cases of BOOP was obtained (Table 3 and 4).

03. The proportion of mononuclear and polymorphonuclear cells in BAL fluid obtained from cases of active pulmonary TB was 58\% and $42 \%$ respectively with a differential cell count of $45.9 \%$ macrophages, $30.8 \%$ lymphocytes, $16.9 \%$ neutrophils and $6.4 \%$ eosinophils (Table 3 and 4).

04. In cases of pneumoconiosis, the proportion of mononuclear cells was increased (84\%). A differential cell count of $62.2 \%$ macrophages, $22.9 \%$ lymphocytes, $13.6 \%$ neutrophils and $1.3 \%$ eosinophils was noted (Table 3 and 4 ).

05. There was an increase in the proportion of polymorphonuclear cells $(64 \%)$ in cases of CEP. A differential cell count of $55.5 \%$ eosinophils, $20.8 \%$ macrophages, $17.4 \%$ lymphocytes, and $6.3 \%$ neutrophils was obtained (Table 3 and 4 ).

06. In cases of asthma, the proportion of mononuclear and polymorphonuclear cells was $84 \%$ and $16 \%$ respectively. A differential cell count of $75.8 \%$ macrophages, $10.2 \%$ lymphocytes, $9.4 \%$ eosinophils and $4.6 \%$ neutrophils was noted (Table 3 and 4 ).

07. There were two cases of adenocarcinoma (AdenoCA) and one case of squamous cell carcinoma (SCC) in the present study. The proportion of mononuclear cells was increased in these cases $(78 \%)$ (Table 3 ). The smears prepared from the BAL fluid of SCC cases showed dispersed keratinized malignant cells of bizarre shapes, eosinophilic cytoplasm and dense hyperchromatic nuclei in a background of necrotic debris. The AdenoCA cases showed sheets and clusters of large columnar cells with abundant delicate cytoplasm and enlarged hyperchromatic nuclei. 


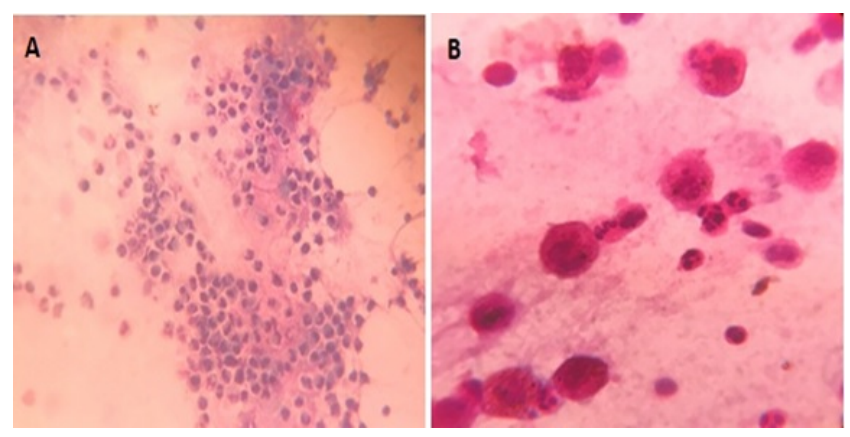

Fig-1 A: BAL smear showing mixed inflammatory cells with a predominance of neutrophils in a case of usual interstitial pneumonia (H and $E, 400 X$ ). B. BAL smear showing carbon laden macrophages in the case of pneumoconiosis ( $H$ and $E, \mathbf{1 0 0 0 X}$ ).

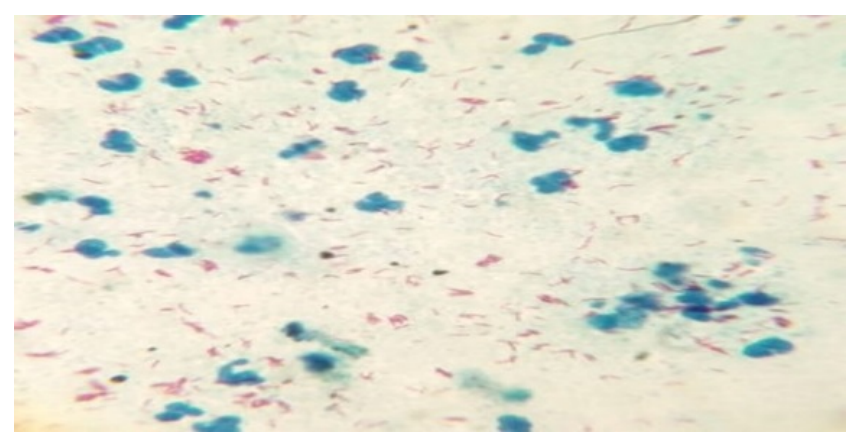

Fig-2: Acid Fast Bacilli in BAL smear. (ZN stain, 1000X)

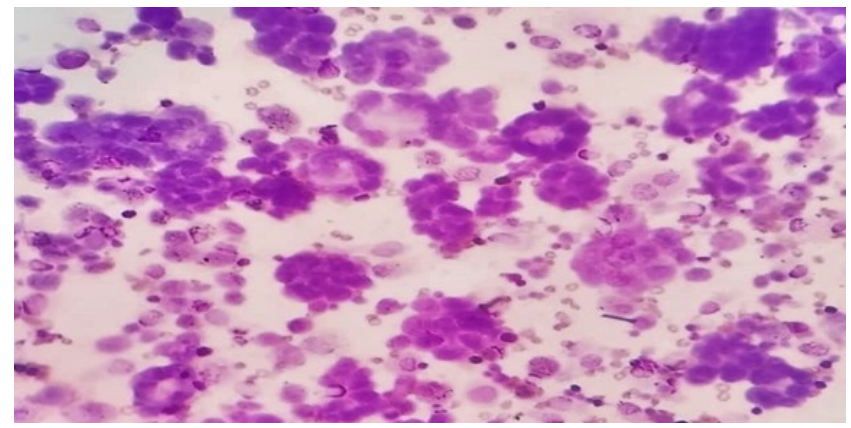

Fig-3: Adenocarcinoma: BAL smear showing tumor cells arranged in an acinar pattern (MGG, 400X).

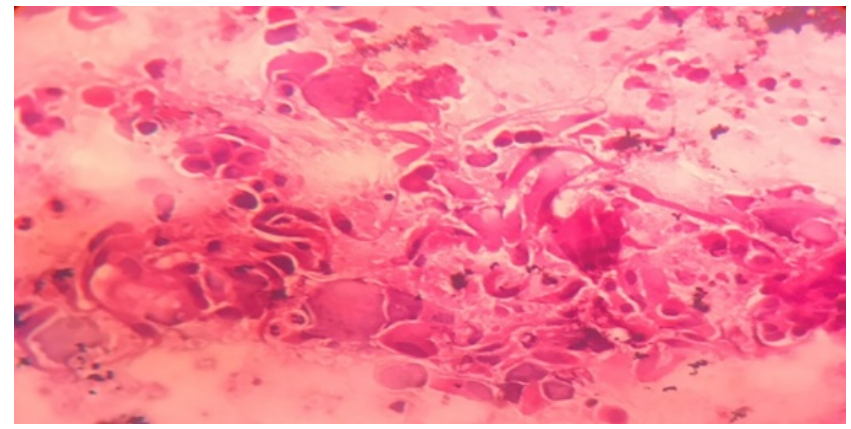

Fig-4: Squamous cell carcinoma: clusters of tumor cells showing pleomorphism, increased
Nucleocytoplasmic ratio and inconspicuous nucleoli in $\mathrm{BAL}$ smears ( $\mathrm{H}$ and $\mathrm{E}, 400 \mathrm{X})$.

Table-4: BAL cellular analysis on sediment smears

\begin{tabular}{|l|l|l|l|l|l|}
\hline Disease & $\begin{array}{c}\text { Total WBC Count } \\
(\mathbf{X 1 0 3} / \mu \mathrm{L})\end{array}$ & $\begin{array}{c}\text { Macropha } \\
\mathrm{ge}(\%)\end{array}$ & $\begin{array}{c}\text { Neutrop } \\
\text { hil }(\%)\end{array}$ & $\begin{array}{c}\text { Lymphocy } \\
\mathrm{te}(\%)\end{array}$ & $\begin{array}{c}\text { Eosinoph } \\
\text { il(\%) }\end{array}$ \\
\hline UIP & 0.053 & 44.4 & 26.2 & 22.2 & 7.2 \\
\hline NSIP & 0.087 & 41.6 & 7.2 & 45.3 & 5.9 \\
\hline BOOP & 0.075 & 52.7 & 8.2 & 35.3 & 3.8 \\
\hline TB & 0.079 & 45.9 & 16.9 & 30.8 & 6.4 \\
\hline $\begin{array}{l}\text { Pneumoc } \\
\text { oniosis }\end{array}$ & 0.031 & 62.2 & 13.6 & 22.9 & 1.3 \\
\hline CEP & 0.090 & 20.8 & 6.3 & 17.4 & 55.5 \\
\hline Asthma & 0.094 & 75.8 & 4.6 & 10.2 & 9.4 \\
\hline
\end{tabular}

\section{Discussion}

The total cell count in bronchoalveolar lavage fluid is routinely measured by a manual method such as haemocytometry and expressed as the number of cells per unit volume. Manual methods have been superseded in the assessment of hematological cell parameters by automated cell counters, because of superior repeatability and the avoidance of many sources of potential error which exist with manual methods [6]. It saves time spent on manually counting cells and the instrument will standardize the analysis of white blood cells across the laboratories currently using various manual counting preparations and procedures [7].

This study involved the diverse submission of BAL samples, in an attempt to quantify the information from differential cell counts. The results demonstrated that cell counts carried information that significantly altered the likelihood of a number of diseases [4]. Numbers of WBC subsets in BAL fluid that deviate from that observed in normal individuals (80-90\% alveolar macrophages, 5-15\% lymphocytes, $\leq 3 \%$ neutrophils, $\leq 1 \%$ eosinophils) are suggestive or consistent with certain forms of diffuse infiltrative lung disease and can be used as an aid to diagnosis when combined with clinical presentation and radiographic appearance $[1,3]$. Pathologic conditions that predominantly affect airways also alter BAL cell profiles [1].

Extreme increases in neutrophils most likely are the result of infection or acute, diffuse lung injury. The present study shows an increase in the percentage of granulocytes in cases of UIP (54\%) on the XNL/350 six-part analyzer. The smears prepared from the BAL fluid of these cases showed similar 
Findings with a differential cell count of $44.4 \%$ macrophages, $26.2 \%$ neutrophils, $22.2 \%$ lymphocytes and $7.2 \%$ eosinophils. This is consistent with the study of Lee $W$. et al which showed a differential cell count of $49.2 \%$ macrophages, $21.2 \%$ neutrophils, $22.1 \%$ lymphocytes and $7.5 \%$ eosinophils in cases of UIP [8].

Lymphocytic cellular pattern $(>15 \%)$ is usually associated with NSIP and BOOP [8]. In the present study, the proportion of mononuclear cells in NSIP and BOOP is $83 \%$ and $88 \%$ respectively on SYSMEX XNL/350 six-part analyzer. The smears prepared from the BAL fluid of NSIP cases showed a differential cell count of $45.3 \%$ lymphocytes, $41.6 \%$ macrophages, $7.2 \%$ neutrophils and $5.9 \%$ eosinophils. The smears prepared from the BAL fluid of BOOP cases showed a differential cell count of $52.7 \%$ macrophages, $35.3 \%$ lymphocytes, $8.2 \%$ neutrophils and $3.8 \%$ eosinophils. This is consistent with the study of Lee $W$. et al which showed $44 \%$ and $34 \%$ of lymphocytes in cases of NSIP and BOOP respectively [8]. Nagai et al reported the mean lymphocyte count of $50 \%$ in their study in cases of NSIP [9].

The number of lymphocytes, neutrophils, and eosinophils is increased in BAL fluid obtained from tuberculous lesions of patients with active pulmonary tuberculosis.[10]. In the present study, the proportion of mononuclear and polymorphonuclear cells in BAL fluid obtained from cases of active pulmonary tuberculosis on SYSMEX XNL/350 six-part analyzer was $58 \%$ and $42 \%$ respectively. The smears prepared from the BAL fluid of TB cases showed a differential cell count of $45.9 \%$ macrophages, $16.9 \%$ neutrophils, $30.8 \%$ lymphocytes and $6.4 \%$ eosinophils. This is consistent with the findings of Ozaki T. et al in their study on differential cell analysis in BAL fluid from pulmonary lesions of patients with tuberculosis. The proportion of macrophages, lymphocytes, neutrophils and eosinophils in their study was $45 \%$, $37.5 \%, 12.5 \%$ and $5 \%$ respectively [10].

There is an increase in lymphocyte count in BAL fluid obtained from cases of occupational lung disease such as pneumoconiosis [1]. In the present study, there were 3 cases working in the Raichur Thermal Power Station and 2 workings as sandblasting and stone cutting workers. The proportion of mononuclear cells on the SYSMEX $\mathrm{XNL} / 350$ six-part analyzer was increased (84\%) in
These cases. The smears prepared from the BAL fluid of cases with pneumoconiosis showed a differential cell count of $62.2 \%$ macrophages (pigment laden), $13.6 \%$ neutrophils, $22.9 \%$ lymphocytes and $1.3 \%$ eosinophils. In the study by Cordeiro C.R. et al on BAL fluid analysis from 20 patients with pneumoconiosis, the proportion of macrophages was found to be $68 \%$, lymphocytes $20 \%$, neutrophils $11 \%$ and eosinophils $1 \%$ [11]. These findings are consistent with the present study. In the study by Kayacan O. et al on BAL fluid analysis from 11 patients with pneumoconiosis, the proportion of macrophages was found to be $94.9 \%$, lymphocytes $2 \%$, neutrophils $3 \%$ and eosinophils $0.1 \%$ which is in contrast with the present study [12].

Increased eosinophils can be seen in many forms of ILD but their numbers on differential cell count usually do not exceed $10 \%$. An eosinophil differential count greater than or equal to $25 \%$ in a patient is highly likely to be caused by eosinophilic pneumonitis [1]. In the present study, there was an increase in the proportion of polymorphonuclear cells $(64 \%)$ on SYSMEX XNL/350 six-part analyzer in cases of chronic eosinophilic pneumonitis (CEP). The smears prepared from the BAL fluid of these cases showed similar findings with a differential cell count of $55.5 \%$ eosinophils, $20.8 \%$ macrophages, $17.4 \%$ lymphocytes, and $6.3 \%$ neutrophils. This is consistent with the studies of Lee $W$. et al which showed a differential cell count of $56.5 \%$ eosinophils, $23.2 \%$ macrophages, $15 \%$ lymphocytes, and 5.3\% neutrophils in eosinophilic pneumonitis [8].

There is an increase in the number of eosinophils in the BAL fluid of asthmatic patients. The present study showed $84 \%$ mononuclear cells and $16 \%$ polymorphonuclear cells on SYSMEX XNL/350 sixpart analyzer. The smears prepared from the BAL fluid of cases with asthma showed a differential cell count of $75.8 \%$ macrophages, $10.2 \%$ lymphocytes, $9.4 \%$ eosinophils, and $4.6 \%$ neutrophils. This is consistent with the findings of Wilson et al who in their study found $91 \%$ macrophages, $3.5 \%$ lymphocytes, $4.5 \%$ eosinophils, and $1 \%$ neutrophils in BAL fluid analysis of asthmatic patients [13].

There were two cases of adenocarcinoma and one case of squamous cell carcinoma in the present study. In non-hematological malignancies of the lung, there is an increase in the number of monocytes in BAL fluid [14].In the present study, 
The proportion of mononuclear cells on the SYSMEX $\mathrm{XNL} / 350$ six-part analyzer was $78 \%$. This is consistent with the study of Sampsonas $F$ et al on BAL fluid samples from 92 cases of nonhematological malignancies showing an increase in the proportion of monocytes (74\%) [14].

In more rare diseases, the potential diagnostic value of BAL cell differentials must be combined with additional clinical and radiographic information to help secure a confident diagnosis and obviate the need to proceed to the more invasive procedure of surgical lung biopsy which is associated with significantly increased risk of morbidity and mortality $[3,4]$.

Automated hematology systems enable a rapid and reliable determination of leukocyte subsets in BAL fluid. Clinicians could make use of BAL fluid cellular profiles to make therapeutic decisions, such as choosing the appropriate site of care or the level of patient monitoring [15].

Limitations of the study: The present study acknowledged the weakness of the study is a small sample size. Larger sample size could have yielded more useful data. Also, the six-part analyzer provides a differential cell count only in terms of mononuclear and polymorphonuclear cells but does not provide a complete differential cell count as obtained using sediment smear slides of the BAL fluid.

\section{Conclusion}

Bronchoalveolar lavage is a widely used primary technique for suspected lung disease patients. Although BAL differential cell counts are not specific markers of diseases, they provide substantial diagnostic information in frequent lung diseases.

\section{What does the study add to the existing knowledge?}

BAL fluid analysis on automated analyzer along with detailed cytology aids to increased diagnostic accuracy in various lung diseases.

\section{Author's contribution}

Dr. Kajal B. Punyashetty: Study concept, design, acquisition of data, analysis, and interpretation of data, compiled literature sources, drafting the manuscripts, checked references, clinical revision.
Dr. Padma Shree Solanki: Study concept, design, acquisition of data, analysis, and interpretation of data, compiled literature sources, drafting the manuscripts, checked references, clinical revision.

Dr. Anand A.: Compiled literature sources, drafting the manuscripts, checked references, clinical revision.

\section{Reference}

01 . Meyer K C. The role of bronchoalveolar lavage in interstitial lung disease. Clin Chest Med. 2004;25(4)637-649.

doi:

[Article:https://doi.org/10.1016/j.ccm.2004.08.001] [Crossref]

02. Kilinc G, Kolsuk E A. The role of bronchoalveolar lavage in diffuse parenchymal lung diseases. Curr Opin Pulm Med. 2005;11(5)417-421.

doi:

[Article:https://doi.org/10.1097/01.mcp.0000175522 .49353.e1][Crossref]

03. Pacinin IFM, Camargos PAM, Marguet C. Cell profile of BAL fluid in children and adolescents with and without lung disease. J Bras Pneumol. 2010;36(3)372-391.

doi: [Article:https://doi.org/10.1590/S180637132010000300016][Crossref]

04. Lee JY, Park HJ, Kim YK, Yu S, Chong YP, Kim $\mathrm{SH}$, et al. Cellular profiles of bronchoalveolar lavage fluid and their prognostic significance for non-HIV-infected patients with Pneumocystis jirovecii pneumonia. J Clin Microbiol. 2015;53(4)1310-1316.

doi: [Article:https://doi.org/10.1128/JCM.03494-14] [Crossref]

05. Welker L, Jorres R A, Costabel U, Magnussen H. Predictive value of BAL cell differentials in the diagnosis of interstitial lung diseases. Eur Respir J. $2004 ; 24 ; 1000-1006$.

doi:

[Article:https://doi.org/10.1183/09031936.04.00101 303][Crossref]

06. Meyer K C. The clinical utility of bronchoalveolar lavage in interstitial lung disease- is it really useful?. Expert Rev Respir Med. 2014;8(2)133135.

doi:

[Article:https://doi.org/10.1586/17476348.2014.879 827][Crossref] 
07. Heaney L G, McKirgan J, Stanford C F, Ennis M. Electronic cell counting to measure total cell numbers in bronchoalveolar lavage fluid. Eur Respir J. 1994;7;1527-1531.

doi:

[Article:https://doi.org/10.1183/09031936.94.07081 527][Crossref]

08. Natiello M, Kelly G, Lamca J, Zelmanovic D, Chapman R W, Phillips J E. Manual and automated leucocyte differentiation in bronchoalveolar lavage fluids from rodent models of pulmonary inflammation. Comp Clin Pathol. 2009;18;101-111.

doi: [Article:https://doi.org/10.1007/s00580-0080772-9][Crossref]

09. Wilson J W, Djukanovic R, Howarth $\mathrm{P} \mathrm{H}$, Holgate $\mathrm{S} \mathrm{T}$. Lymphocyte activation in bronchoalveolar lavage and peripheral blood in atopic asthma. Am Rev Respir Dis. 1992;145(4)958-960.

doi:

[Article:https://doi.org/10.1164/ajrccm/145.4_Pt_1.9 58][Crossref]

10. Cordeiro C R, Jones J C, Alfaro T, Ferreira A J. Bronchoalveolar lavage in occupational lung diseases. Semin RespirCrit Care Med. 2007;28(5)504-513.

doi: [Article:https://doi.org/10.1055/s-2007-991523]

[Crossref]

11. Kayacan O, Beder S, Karnak D. Cellular profile of bronchoalveolar lavage fluid in Turkish miners. Postgrad Med J. 2003;79(935)527-530. doi:

[Article:http://dx.doi.org/10.1136/pmj.79.935.527]

[Crossref]
12. Lee W, Chung W S, Hong K S, Huh J. Clinical usefulness of bronchoalveolar lavage cellular analysis and lymphocyte subsets in diffuse interstitial lung diseases. Ann Lab Med. $2015 ; 35(2) 220-225$.

doi:

[Article:https://doi.org/10.3343/alm.2015.35.2.220] [Crossref]

13. Nagai $S$, Kitaichi $M$, Itoh $H$, Nishimura $K$, Izumi $\mathrm{T}$, Colby $\mathrm{T}$ V. Idiopathic nonspecific interstitial pneumonia/fibrosis- comparison with idiopathic pulmonary fibrosis and BOOP. Eur Respir J. $1998 ; 12 ; 1010-1019$.

doi:

[Article:https://doi.org/10.1183/09031936.98.12051 010][Crossref]

14. Ozaki T, Nakahira S, Tani K, Ogushi F, Yasuoka $S$, Ogura T. Differential cell analysis in bronchoalveolar lavage fluid from pulmonary lesions of patients with tuberculosis. Chest. 1992;102(1)54-59.

doi: [Article:https://doi.org/10.1378/chest.102.1.54] [Crossref]

15. Sampsonas F, Kontoyiannis D P, Dickey B F, Evans $S$ E. Performance of a standardized Bronchoalveolar lavage protocol in a comprehensive cancer center. Cancer. 2011;117(15)3424-3433.

doi: [Article:https://doi.org/10.1002/cncr.25905] [Crossref] 